\title{
Dental Caries Experience in 6-13 Years Old School Children of Dharan Sub-Metropolitan City, Nepal: A Cross-Sectional Study
}

\author{
Bhawana Sigdel Bastola, ${ }^{1}$ Bandana Koirala, ${ }^{2}$ Mamta Dali, ${ }^{3}$ Sneha Shrestha, ${ }^{4}$ Dharanidhar Baral ${ }^{5}$ \\ ${ }^{1}$ Lecturer, ${ }^{2}$ Professor, ${ }^{3}$ Associate Professor, ${ }^{4,5}$ Assistant Professor \\ ${ }^{1}$ Department of Dentistry, Pokhara Academy of Health Science, Pokhara, Nepal, \\ ${ }^{2-4}$ Department of Pedodontics and Preventive Dentistry, College of Dental Surgery, \\ ${ }^{5}$ School of Public Health and Community Medicine, B.P. Koirala Institute of Health Sciences, Dharan, Sunsari, Nepal.
}

\section{ABSTRACT}

Introduction: Dental caries though preventable oral health problem is affecting school children worldwide and around 50\% of Nepalese children are suffering from it. Baseline data with good understanding of dental caries and associated risk factors are necessary to form preventive strategies for setting and achieving oral health goals.

Objective: This study was conducted to determine dental caries experience and associated risk factors among school-going children of 6-13 years old in Dharan sub-metropolitan city,Nepal.

Methods: A cross-sectional study was conducted from $5^{\text {th }}$ Jan 2018 to 4th Jan 2019 among 680 school children selected by multistage cluster sampling method. Pretested, standardized, closed-ended questionnaire answered by the parents was used to gather information regarding the associated risk factors. Dental caries experience was obtained from deft/DMFT (WHO modification 1997). Comparison of categorical data was done using Chi-square test. Multivariable binary logistic regressions were used for the statistical analysis.

Results: The overall caries prevalence was $61.6 \%$,in primary dentition it was $48.25 \%$ and in permanent dentition it was $34.4 \%$. Dental caries experience was with mean deft 4.67 ( \pm 2.7$)$ in primary dentition and mean DMFT $1.72( \pm 1.05)$.in permanent dentition. Multivariate analysis showed significant association between dental caries experience and grade three and grade four school children had experienced greater caries $(\mathrm{p}<0.05, \mathrm{OR}=2.7)$. Dental caries was associated with eating sweets at night $(\mathrm{p}<0.001, \mathrm{OR}=2.5)$ and snacking in-between meals $(\mathrm{p}<0.001, \mathrm{OR}=2.5)$.

Conclusions: Dental caries among school-children in Dharan showed a significant burden especially within the primary dentition. It was significantly associated with factors like feeding habits -eating sweets in a day,eating sweets at night and snaking in between meals.

Keywords: Dental caries, risk factors, school children.

\section{INTRODUCTION}

Dental caries is one of the major global oral health problems as it affects majority of school children worldwide. ${ }^{1}$ It is

\section{Correspondence}

Dr. Bhawana Sigdel Bastola

Lecturer,Pokhara Academy of Health Science,Pokhara, Nepal

E-mail: bhawana.sigdel@gmail.com

\section{Citation}

Bastola S B, Koirala B, Dali M, Shrestha S, Baral D.wal SK. Dental Caries Experience in 6-13 Years Old School Children of Dharan Sub-Metropolitan City, Nepal: A Cross-Sectional Study. J Nepal Assoc Pediatr Dent. 2021;2(1):12-8. an emerging public health problem amongst the child population in Nepal. A study done in eastern Nepal found dental caries to be $60.3 \%$ and $55.6 \%$ in the primary and permanent dentition, respectively. ${ }^{2}$

Dental caries is a multifactorial disease. Studies have established relative importance of associated factor with dental caries experience like parent's low education, unemployment, low income, cariogenic diet all affecting caries risk. ${ }^{3.5}$ There is a strong scientific support for the efficacy of fluoridated toothpaste and frequency of tooth brushing to have a significant association with caries prevalence..$^{6-8}$ Food habit is another factor having greater influence in dental caries. ${ }^{9}$ Caries risk is increased if the 
sugar is consumed between-meals and in a form which adheres to the teeth. ${ }^{10}$ Untreated dental caries with the prevalence of $58 \%$ in young Nepalese children is more than malnutrition that affects $53 \%$ of the child population. ${ }^{11}$

Childhood dental caries is a serious dental public health problem that warrants immediate attention of the government and dental profession officials. Hence, this study aimed to assess the dental caries experience and its associated risk factors in 6-13 years old school children in Dharan sub-metropolitan city.

\section{METHODS}

It was a descriptive cross-sectional study conducted amongst 6-13 years old school children of Dharan submetropolitan city of eastern Nepal. Ethical clearance was obtained from the Institutional Review Committee (IRC) with reference number (226/074/075), BPKIHS, Dharan. Duration of the study was one year from 5th Jan 2018 to 4th Jan 2019. Dental caries experience was obtained from deft/DMFT (WHO modification 1997). Modification of Kuppuswamy's socioeconomic status scale in context to Nepal was used to access the socioeconomic status. ${ }^{12}$

Sample size for this study had been calculated considering $56 \%$ prevalence of dental caries from the study done by Bhagat TK et al. ${ }^{2}$

For prevalence studies,

$$
\mathrm{n}=\frac{\mathrm{Z}_{\alpha}^{2 \times} \mathrm{p}^{\times} \mathrm{q}}{\mathrm{L}^{2}}
$$

Where, $\mathrm{n}=$ sample size, $\mathrm{Z}_{\alpha}=\mathrm{Z}$ statistic for a level of confidence.

At $95 \%$ confidence interval where alpha error $=10 \%$, $\mathrm{Z}_{\alpha}=1.96$

$\mathrm{p}=$ Expected prevalence $=56 \%, \mathrm{q}=1-\mathrm{p}=44 \%$

$\mathrm{L}=$ Precision $=10 \%$ of $\mathrm{p}$ that is $5.6 \%$

On calculation,

$$
\begin{aligned}
& \mathrm{n}=\frac{\mathrm{Z}_{a}^{2 \times} \mathrm{p}^{\times} \mathrm{q}}{\mathrm{L}^{2}} \\
& \mathrm{n}=\frac{(1.96)^{2} \times 56 \times 44}{(5.6)^{2}}
\end{aligned}
$$

$=301.84=302$ (rounding off)
Considering design effect of 2 the final sample size, $\mathrm{n}=302 \times 2=604$

Now, adding $10 \%$ in calculation for non-response, the sample size had become 680 .

Multistage cluster sampling method was employed for the study. There was a total of 134 schools (44 public and 90 private) in Dharan sub-metropolitan city, out of which10\% of the schools were chosen. Five public and ten private schools were selected randomly by lottery method in the ratio of 1:2,taking care for including schools from different wards of Dharan. A cluster size of 40 students was then formed. Since around 17 clusters were needed, based on the number of students, five clusters (a total of 200 students) and 12 clusters (total 480 students) were chosen from the five public and ten private schools, respectively. Likewise, six to seven students from each grade (from grade one to six) were chosen by a random number table.

Cooperative, 6-13 years old school going children whose parents were willing to participate in the study was included. All those children whose parents did not give consent were excluded. Prior to data collection, written informed consent were obtained from the parents through their children by sending the information sheet,informed consent form, and the questionnaire. A pretested, standardized, modified, closed-ended questionnaire was used to gather information regarding the associated risk factors. After taking the assent from children, they were then requested to open their mouth to be examined under the natural daylight. Drying of the field of examination was obtained with gauze by a single examiner following standard protocols.

Collected data was then entered in Microsoft Excel 2013. Accuracy of data entry was rechecked after every 10 entries. The obtained data was converted into Statistical Package for Social Sciences (SPSS) 11.5 version for the statistical analysis. The comparison of categorical data was done using Chi-square test. Logistic regression was used to find out the adjusted effect of associated risk factors and demographic variables to dental caries. The level of significance was set at $\mathrm{p}<0.05$.

\section{RESULTS}

A total of 680 children studying in the private and public schools of Dharan were included in the study. Majority of the children belonged to private schools. Distribution 
of children according to different sociodemographic variables is given in Table 1 . Similarly, oral hygiene habits,feeding habits, and dental visit of the children were assessed and the results are shown in Table 2.
The overall dental caries prevalence in the present study was found to be $61.6 \%$, of which primary dentition was $48.25 \%$ and permanent dentition was found to be $34.4 \%$. Whereas,dental caries experience was with mean deft \pm S.D

Table 1. Distribution of children according to sociodemographic variables $(n=680)$.

\begin{tabular}{|c|c|c|c|}
\hline Characteristics & Categories & Number of Children & Percentage \\
\hline \multirow{2}{*}{ Gender } & Male & 333 & 49.0 \\
\hline & Female & 347 & 51.0 \\
\hline \multirow{2}{*}{ Type of School } & Public & 200 & 29.4 \\
\hline & Private & 480 & 70.6 \\
\hline \multirow{6}{*}{ Grade } & 1 & 109 & 16.0 \\
\hline & 2 & 121 & 17.8 \\
\hline & 3 & 122 & 17.9 \\
\hline & 4 & 113 & 16.6 \\
\hline & 5 & 108 & 15.9 \\
\hline & 6 & 107 & 15.8 \\
\hline \multirow{5}{*}{ Socioeconomic Status } & Upper & 64 & 9.4 \\
\hline & Upper Middle & 209 & 30.6 \\
\hline & Lower Middle & 200 & 29.5 \\
\hline & Upper Lower & 200 & 29.5 \\
\hline & Lower & 7.0 & 1.0 \\
\hline
\end{tabular}

Table 2. Distribution of children according to oral hygiene habits, feeding habits and dental visit $(n=680)$.

\begin{tabular}{|c|c|c|c|c|}
\hline Variables & Characteristics & Categories & Number of Children & Percentage \\
\hline \multirow{12}{*}{$\begin{array}{l}\text { Oral } \\
\text { Hygiene } \\
\text { Habits }\end{array}$} & \multirow{2}{*}{ Brushing habit } & Yes & 675 & 99.3 \\
\hline & & No & 5.0 & 0.7 \\
\hline & \multirow{2}{*}{$\begin{array}{l}\text { Frequency of brushing } \\
\text { per day }\end{array}$} & 1 & 318 & 47.1 \\
\hline & & $>2$ & 357 & 52.9 \\
\hline & \multirow{3}{*}{ Type of toothpaste } & Fluoridated Paste & 506 & 75.0 \\
\hline & & Non-fluoridated & 166 & 24.5 \\
\hline & & Others: Neem,Charcoal,Datiwan & 3.0 & 0.5 \\
\hline & \multirow{3}{*}{$\begin{array}{l}\text { Tooth brush introduced } \\
\text { to child (years of age) }\end{array}$} & 2 & 136 & 20.0 \\
\hline & & $>2$ & 539 & 79.3 \\
\hline & & Not introduced till now & 5.0 & 0.7 \\
\hline & \multirow{2}{*}{ Mouth rinsing habit } & Yes & 572 & 84.1 \\
\hline & & No & 108 & 15.9 \\
\hline \multirow{11}{*}{$\begin{array}{l}\text { Feeding } \\
\text { Habits }\end{array}$} & \multirow{3}{*}{ Eating sweets in a day } & Hardly ever & 441 & 64.9 \\
\hline & & One time per day & 134 & 19.7 \\
\hline & & 2 per day & 105 & 15.4 \\
\hline & \multirow{2}{*}{$\begin{array}{l}\text { Snacking in- between } \\
\text { meals }\end{array}$} & Yes & 537 & 79.0 \\
\hline & & No & 143 & 21.0 \\
\hline & \multirow{2}{*}{ Eating sweets at night } & Yes & 143 & 21.0 \\
\hline & & No & 537 & 79.0 \\
\hline & \multirow{4}{*}{$\begin{array}{l}\text { Frequency of taking soft } \\
\text { drinks/juice }\end{array}$} & Daily & 96 & 14.1 \\
\hline & & Weekly & 26 & 3.8 \\
\hline & & Occasionally & 528 & 77.6 \\
\hline & & Don't take it & 30 & 4.5 \\
\hline \multirow{4}{*}{$\begin{array}{l}\text { Dental } \\
\text { Visit }\end{array}$} & \multirow{2}{*}{ Dental visit } & Yes & 280 & 41.2 \\
\hline & & No & 400 & 58.8 \\
\hline & \multirow{2}{*}{ Time of dental visit } & $<6$ months & 87 & 31.1 \\
\hline & & $\geq 6$ months & 193 & 68.9 \\
\hline
\end{tabular}


of $4.67 \pm 2.7$ and mean defs \pm S.D of $9.45 \pm 9.85$ in primary dentition and dental caries experience in the permanent dentition was found to be with mean DMFT \pm S.D of $1.72 \pm 1.05$ and mean DMFS \pm S.D of $1.83 \pm 1.45$. In case of decayed, missing or extracted and filled individual components in the primary and the permanent dentitions, decayed portion was seen to be the highest,primary (42.1\%) and permanent (32.8\%). Missing/extracted component in the primary dentition and permanent dentition were found to be $16.8 \%$ and $0.3 \%$ respectively, whereas, filled component in the primary dentition and permanent dentition were found to be $7.1 \%$ and $1.9 \%$ respectively.

The tooth-wise distribution of dental caries experience in case of permanent teeth showed first permanent molars to be the most commonly decayed teeth with $22.9 \%$ in mandibular right first molars and $18.1 \%$ in mandibular left first molars followed by maxillary right and left first molars

Table 3. Association of sociodemographic, oral hygiene habits, feeding habits and dental visit, with dental caries experience $(n=680)$.

\begin{tabular}{|c|c|c|c|c|c|}
\hline \multirow{2}{*}{ Variables } & \multirow{2}{*}{ Characteristics } & \multirow{2}{*}{ Categories } & \multicolumn{2}{|c|}{ Caries Experience in (\%) } & \multirow{2}{*}{$P$ value } \\
\hline & & & No & Yes & \\
\hline \multirow{14}{*}{$\begin{array}{l}\text { Sociode- } \\
\text { mographic }\end{array}$} & \multirow{2}{*}{ Gender } & Female & $136(39.2)$ & $211(60.8)$ & \multirow{2}{*}{$0.657^{*}$} \\
\hline & & Male & $125(37.5)$ & $208(62.5)$ & \\
\hline & \multirow{6}{*}{ Grade } & 1 & $46(42.2 \%)$ & $63(57.8 \%)$ & \multirow{6}{*}{$<0.001^{*}$} \\
\hline & & 2 & $37(30.6 \%)$ & $84(69.4 \%)$ & \\
\hline & & 3 & $34(27.9 \%)$ & $88(72.1 \%)$ & \\
\hline & & 4 & $41(36.3 \%)$ & $72(63.7 \%)$ & \\
\hline & & 5 & $44(40.7 \%)$ & $64(59.3 \%)$ & \\
\hline & & 6 & $59(55.1 \%)$ & $48(44.9 \%)$ & \\
\hline & \multirow{2}{*}{ School type } & Public & $87(43.5 \%)$ & $113(56.5 \%)$ & \multirow{2}{*}{$0.077^{*}$} \\
\hline & & Private & $174(36.3 \%)$ & $306(63.8 \%)$ & \\
\hline & \multirow{4}{*}{ Socioeconomic status } & Upper & $21(32.8 \%)$ & $43(67.2 \%)$ & \multirow{4}{*}{$0.410^{*}$} \\
\hline & & Upper Middle & $75(35.9 \%)$ & $134(64.1 \%)$ & \\
\hline & & Lower Middle & $77(38.5 \%)$ & $123(61.5 \%)$ & \\
\hline & & Upper Lower & $88(42.5 \%)$ & $119(57.5 \%)$ & \\
\hline \multirow{10}{*}{$\begin{array}{l}\text { Oral } \\
\text { Hygiene } \\
\text { Habits }\end{array}$} & \multirow{2}{*}{ Brushing habit } & Yes & $261(38.7 \%)$ & $414(61.3 \%)$ & \multirow{2}{*}{$0.162 \$$} \\
\hline & & No & $0.0(.0 \%)$ & $5.0(100.0 \%)$ & \\
\hline & \multirow{2}{*}{$\begin{array}{l}\text { Frequency of brushing } \\
\text { per day }\end{array}$} & 1 & $115(36.2 \%)$ & $203(63.8 \%)$ & \multirow{2}{*}{$0.208^{*}$} \\
\hline & & $>2$ & $146(40.9 \%)$ & $211(59.1 \%)$ & \\
\hline & \multirow{2}{*}{ Type of toothpaste } & Fluoridated & $206(40.7 \%)$ & $300(59.3 \%)$ & \multirow{2}{*}{$0.059^{*}$} \\
\hline & & Non Fluoridated & $55(32.5 \%)$ & $114(67.5 \%)$ & \\
\hline & \multirow{2}{*}{$\begin{array}{l}\text { Tooth brush introduced } \\
\text { to child in years of age }\end{array}$} & 2 & $54(39.7 \%)$ & $82(60.3 \%)$ & \multirow{2}{*}{$0.781^{*}$} \\
\hline & & $>2$ & 207 (38.4\%) & $332(61.6 \%)$ & \\
\hline & \multirow{2}{*}{ Mouth rinsing habit } & Yes & $228(39.9 \%)$ & $344(60.1 \%)$ & \multirow{2}{*}{$0.068^{*}$} \\
\hline & & No & $33(30.6 \%)$ & $75(69.4 \%)$ & \\
\hline \multirow{11}{*}{$\begin{array}{l}\text { Feeding } \\
\text { Habits }\end{array}$} & & Hardly Ever & $187(42.4 \%)$ & $254(57.6 \%)$ & \\
\hline & Eating sweets in a day & One Time Per Day & $45(33.6 \%)$ & $89(66.4 \%)$ & $<0.001^{*}$ \\
\hline & & 2 Per Day & $29(27.6 \%)$ & $76(72.4 \%)$ & \\
\hline & Snacking in-between & Yes & $180(33.5 \%)$ & $357(66.5 \%)$ & $<0001$ * \\
\hline & meals & No & $81(56.6 \%)$ & $62(43.4 \%)$ & $<0.001$ \\
\hline & & Yes & $30(21.0 \%)$ & $113(79.0 \%)$ & \\
\hline & Eatıng sweets at night & No & $231(43.0 \%)$ & $306(57.0 \%)$ & $<0.001^{*}$ \\
\hline & & Daily & $18(18.8 \%)$ & $78(81.3 \%)$ & \\
\hline & Frequency of taking soft & Weekly & $9.0(34.6 \%)$ & $17(65.4 \%)$ & \\
\hline & drinks/juice & Occasionally & $219(41.5 \%)$ & $309(58.5 \%)$ & $<0.001^{*}$ \\
\hline & & Don't Take It & $15(50.0 \%)$ & $15(50.0 \%)$ & \\
\hline & Dental visit & Yes & $81(28.9 \%)$ & $199(71.1 \%)$ & $<0001$ * \\
\hline Dental & Dental visit & No & $180(45.0 \%)$ & $220(55.0 \%)$ & $<0.001$ \\
\hline Visit & Time of dental visit & $<6$ month & $19(21.8 \%)$ & $68(78.2 \%)$ & $<0001$ * \\
\hline & lime of dental visit & 6 month & $62(32.1 \%)$ & $131(67.9 \%)$ & $<0.001$ \\
\hline
\end{tabular}

Fisher's Exact Test\$, Chi square test * 
Table 4. Multivariate regression model for risk factors for dental caries experience.

\begin{tabular}{|c|c|c|c|c|c|}
\hline \multirow{2}{*}{ Variable Equation } & \multirow{2}{*}{$\beta$ coefficient } & \multirow{2}{*}{$P$ value } & \multirow{2}{*}{ Odds Ratio } & \multicolumn{2}{|c|}{ 95\% C.I. for Odds Ratio } \\
\hline & & & & Lower & Upper \\
\hline Age in years & -0.137 & 0.066 & 0.872 & 0.753 & 1.009 \\
\hline \multicolumn{6}{|l|}{ Grade } \\
\hline Grade 1 & \multicolumn{5}{|c|}{ Reference category } \\
\hline Grade 2 & 0.629 & 0.041 & 1.875 & 1.025 & 3.432 \\
\hline Grade 3 & 0.993 & 0.005 & 2.700 & 1.360 & 5.361 \\
\hline Grade 4 & 0.696 & 0.076 & 2.005 & 0.930 & 4.326 \\
\hline Grade 5 & 0.423 & 0.334 & 1.527 & 0.647 & 3.604 \\
\hline Grade 6 & -0.058 & 0.909 & 0.944 & 0.350 & 2.544 \\
\hline \multicolumn{6}{|l|}{ Type of School } \\
\hline Public & \multicolumn{5}{|c|}{ Reference category } \\
\hline Private & 0.073 & 0.727 & 1.076 & 0.713 & 1.625 \\
\hline \multicolumn{6}{|l|}{ Mouth Rinsing Habit } \\
\hline Yes & \multicolumn{5}{|c|}{ Reference category } \\
\hline No & 0.577 & 0.022 & 1.780 & 1.087 & 2.916 \\
\hline \multicolumn{6}{|c|}{ Frequency of Eating Sweets in a Day } \\
\hline Hardly ever & \multicolumn{5}{|c|}{ Reference category } \\
\hline One time & 0.065 & 0.781 & 1.067 & 0.675 & 1.686 \\
\hline 2 & 0.197 & 0.480 & 1.218 & 0.704 & 2.106 \\
\hline \multicolumn{6}{|l|}{ Snacking in-between Meals } \\
\hline No & \multicolumn{5}{|c|}{ Reference category } \\
\hline Yes & 0.749 & 0.001 & 2.114 & 1.348 & 3.318 \\
\hline \multicolumn{6}{|l|}{ Eating Sweets at Night } \\
\hline No & \multicolumn{5}{|c|}{ Reference category } \\
\hline Yes & 0.953 & $<0.001$ & 2.593 & 1.584 & 4.244 \\
\hline \multicolumn{6}{|c|}{ Frequency of Taking Soft Drinks } \\
\hline Daily & \multicolumn{5}{|c|}{ Reference category } \\
\hline Weekly & -0.495 & 0.352 & 0.609 & 0.215 & 1.729 \\
\hline Occasionally & -0.776 & 0.010 & 0.460 & 0.254 & 0.833 \\
\hline Don't take it & -0.793 & 0.114 & 0.453 & 0.169 & 1.209 \\
\hline \multicolumn{6}{|l|}{ Dental Visit } \\
\hline Yes & \multicolumn{5}{|c|}{ Reference category } \\
\hline No & -0.649 & $<0.001$ & 0.522 & 0.363 & 0.751 \\
\hline Constant & -0.246 & 0.793 & 0.782 & & \\
\hline \multicolumn{2}{|c|}{$\begin{array}{l}\text { with only } 4.1 \% \text { involvement. Whereas, in the primary } \\
\text { dentition, mandibular right second molars was affected } \\
\text { in } 23.7 \% \text { of the cases followed by mandibular left second } \\
\text { molar }(21.6 \%) \text {. However, mandibular anterior teeth were } \\
\text { the least affected i.e.,just } 0.1 \% \text {. Surface-wise distribution } \\
\text { on both the primary and permanent teeth showed occlusal } \\
\text { surface to be the most commonly decayed one. }\end{array}$} & \multicolumn{4}{|c|}{$\begin{array}{l}\text { caries experience is shown in Table } 3 \text {. The variables which } \\
\text { were associated with dental caries experience and variables } \\
\text { with less than } \mathrm{p}<0.20 \text { from bivariate analysis were included } \\
\text { into multivariate binomial logistic regression analysis after } \\
\text { controlling for confounder such as tooth brushing. No- } \\
\text { caries was taken as a reference category and compared } \\
\text { with the caries experience group and inferred with the help } \\
\text { of adjusted odds and } 95 \% \text { confidence interval to interpret } \\
\text { the findings. The final binomial logistic regression analysis } \\
\text { on the dental caries experience is shown in Table } 4 \text {. }\end{array}$} \\
\hline
\end{tabular}




\section{DISCUSSION}

The present study was done in the schools, as it is considered as a miniature model of larger community and one of the best places for oral health promotion where all children, irrespective of their gender, socioeconomic status, and ethnicity can be reached. In the present study, dental caries was found to be significantly associated with feeding habits like eating sweets in a day and at night, snacking in between meals and time of dental visit. It was also found that more than half of the children (61.6\%) experienced dental caries, of which $48.25 \%$ involved primary teeth with the mean deft of $4.67( \pm 2.7)$ and $34.40 \%$ permanent teeth with the mean DMFT of $1.72( \pm 1.05)$. Prevalence of dental caries in primary dentition was lower in the present study as compared to the studies conducted by Dixit LP et al. ${ }^{13}(52 \%)$ and Thapa $\mathrm{P}$ et al. ${ }^{14}$ (64.4\%). Similarly, in case of permanent dentition, the dental caries experience reported by Shrestha N et al. ${ }^{15}$ (42.6\%), Dixit LP et al. ${ }^{13}$ (41.0\%), Bhagat TK et al. ${ }^{2}$ (56.0\%), and Thapa P et al. ${ }^{14}(42.2 \%)$ was higher than that found in the present study $(34.40 \%)$.

Male participants experienced more caries (62.5\%) compared to the female participants (60.8\%) in the present study, but this association was not statistically significant $(p=0.657)$. In Nepal, majority of the upper and uppermiddle socioeconomic class have been shown to afford to send their children to private schools. ${ }^{16,17}$ Present study showed children from private schools (63.8\%) experienced higher dental caries compared to their public (56.5\%) counterparts. Similar finding was reported by Basha et al. ${ }^{4}$ However, this association was also not seen to be statistically significant $(\mathrm{p}=0.077)$.

In the present study, among 680 children, 675 brushed their teeth, whereas findings of Dixit LP et al. reported very poor brushing habit of 56\%.13 Only 414 (61.3\%) out of 675 experienced caries while remaining five who did not brush their teeth had $100 \%$ caries experience and this finding was statistically significant $(\mathrm{p}=0.162)$. Similarly, $203(63.8 \%)$ children who brushed their teeth once or less every day showed more caries experience than those who brushed their teeth more than once daily. Again, children who used non-fluoridated toothpaste (67.5\%) had higher caries experience than $59.3 \%$ of children who used fluoridated toothpaste. This proves the importance of efficacy of regular tooth brushing with fluoridated toothpaste in minimizing the caries occurrence,especially in children of our part of Nepal where fluoride level was below the optimal value of Nepal $(0.5 \mathrm{mg} / 1) .{ }^{18}$
Generally in Nepal, parents wait for their child to reach three to four years of age to introduce tooth brushing to them which is contrary to the need for start of early caries preventive efforts. ${ }^{19}$ It was thus found, only few i.e., 136 (20.1\%) to have brushed below two years and most of the children $539(79.3 \%)$ to have brushed their teeth only after they reached more than two years of age. Among them, $61.6 \%$ of the children experienced caries compared to the $60.3 \%$ who brushed at age less than two years.

Rinsing of the mouth with water after meal is also a common practice in Nepal. ${ }^{16}$ Similar practice was observed in the present population with maximum children (84.1\%) having the habit of mouth-rinsing. Children who did not rinse their mouth experienced more caries,i.e., 1.78 times than those who practiced mouth-rinsing habit,and this association was found to be significant $(\mathrm{p}=0.022)$.

Frequency of consuming sweets was directly related to the caries experience in the present study. Similarly,113 children (79.0\%) who used to consume sweets at night had greater caries experience i.e.,2.5 times more than those who did not consume sweets at night 306 (57.0\%). Present findings were also supported by the study of Lueangpiansamut $J$ et al with significant association $(p=<0.001)$ of sweets consumption before bedtime to increase dental caries. ${ }^{19}$

Majority of the children i.e.,537 (79\%) also had the habit of snacking in-between meals. Among them,we observed 357 $(66.5 \%)$ children to have higher caries experience (2.1 times greater) than those who did not have this snacking habit i.e., in $62(43.4 \%)$. Snacking has been a risk indicator for caries development in children as evident from other studies as well. ${ }^{19-21}$ It was also found that more than half, i.e., $58.8 \%$ of the children never visited the dentist, whereas, $41.8 \%$ of them had visited at least once and among them also 71.1\% of children experienced caries. Findings of Khanal S et al. ${ }^{22}$ showed the dental visit to be very poor (only 5.6\%) and among them $77.4 \%$ visited only when they had pain. In the present study, only clinical examination was done and no radiographs were taken, which might have underestimated the actual magnitude of the problem and also,true results might have been obscured due to the incorrect reporting (recall bias) to questions that were answered by the parents regarding children's oral hygiene and feeding habits. Thus, this study has elucidated that dental caries is still a major affliction in our children population and urgent start for implementation of awareness programs for promoting early preventive measures hold utmost importance for uplifting the oral health status of the children of Dharan sub-metropolitan city. 


\section{CONGLUSIONS}

The dental caries prevalence was found to be high (61.6\%) with more of the decayed component in both the primary (42.1\%) and permanent (32.8\%) teeth. Children from grade three $(72.1 \%)$ and grade four (63.7\%) experienced greater caries. Similarly,the main associated risk factors for dental caries were feeding habits like eating sweets at night, snacking in-between meals,and lack of oral hygiene habits like mouth-rinsing habit. The findings from the present study thus mandate parents and health professionals to emphasize implementation and improvement of preventive measures at an early age.

\section{ACKNOWLEDGEMENTS}

I would like to express my deepest gratitude to Prof. Dr. Surya Raj Niraula and Dr. Santosh Kumari Agrawal for their invaluable effort in conducting statistical analysis of the manuscript. Lastly, I would also like to thank all the schools,parents and the children who have agreed to partici pate in our research.

\section{Conflict of Interest: None}

\section{REFERENCES}

1. Kazeminia M,Abdi A,Shohaimi S,Jalali R,Vaisi-Raygani A,Salari N,Mohammadi M. Dental caries in primary and permanent teeth in children's worldwide,1995 to 2019: a systematic review and meta-analysis. Head Face Med. 2020 Oct 6;16(1):22. [PubMed I DOI]

2. Bhagat TK,Shrestha A. Dental caries experience among school children of Eastern Nepal-significant caries index. Health Renaissance. 2015 Dec;12(2):74-7. [Full Text | DOI]

3. David J,Wang NJ,Astrøm AN,Kuriakose S. Dental caries and associated factors in 12-year-old schoolchildren in Thiruvananthapuram,Kerala,India. Int J Paediatr Dent. 2005 Nov;15(6):420-8. [PubMed | DOI]

4. Basha S,Swamy HS. Dental caries experience,tooth surface distribution and associated factors in 6- and 13-year- old school children from Davangere,India. J Clin Exp Dent. 2012 Oct 1;4(4):e210-6. [PubMed | Full Text | DOI]

5. Antunes JL,Narvai PC,NugentZJ. Measuring inequalities in the distribution of dental caries. Community Dent Oral Epidemiol. 2004 Feb;32(1):41-8. [PubMed | DOI]

6. Tenuta LM,Cury JA. Fluoride: its role in dentistry. Braz Oral Res. 2010;24 Suppl 1:9-17. [PubMed I DOI]

7. Marinho VC, Higgins JP, Sheiham A, Logan S. Fluoride toothpastes for preventing dental caries in children and adolescents. Cochrane Database Syst Rev. 2003;(1):CD002278. [PubMed | DOI]

8. Julihn A,Barr Agholme M,Grindefjord M,Modéer T. Risk factors and risk indicators associated with high caries experience in Swedish 19-year-olds. Acta Odontol Scand. 2006 Oct;64(5):267-73. [PubMed I DOI]

9. Gustafsson BE, Quensel CE, Lanke LS Lundqvist C, Grahnen H, Bonow BE, Krasse B. The Vipeholm dental caries study; the effect of different levels of carbohydrate intake on caries activity in 436 individuals observed for five years. Acta Odontol Scand. 1954 Sep;11(3-4):232-64. [ [PubMed | DOI]

10. Touger-Decker R,van Loveren C. Sugars and dental caries. Am J Clin Nutr. 2003 Oct;78(4):881S-892S. [ubMed | DOI]

11. National oral health policy. Retrieved 5 April 2021. Available from: https://www.mohp.gov.np. [Full Text]

12. Ghosh A,Ghosh T. Modification of Kuppuswamys socioeconomic status scale in context to Nepal. Indian Pediatr. 2009 Dec;46(12):1104-5. [PubMed | Full Text]

13. Prasai Dixit L,Shakya A,Shrestha M,Shrestha A. Dental caries prevalence, oral health knowledge and practice among indigenous Chepang school children of Nepal. BMC Oral Health. 2013 May 14;13:20. [ublMed I DOI]

14. Thapa P,Aryal KK,Dhimal M,Mehata S,Pokhrel AU,Pandit A,Pandey AR,Bista B,Dhakal P,Karki KB,Pradhan S. Oral Health Condition of School Children in Nawalparasi District,Nepal. J Nepal Health Res Counc. 2015 Jan-Apr;13(29):7-13. [uㅣㅣㄹ]

15. Shrestha N,Acharya J,Sagtani AR,Shrestha R,Shrestha S. Occurrence of dental caries in primary and permanent dentition,oral health status and treatment needs among 12-15 year old school children of Jorpati VDC,Kathmandu. Nepal Med Coll J. 2014 Dec;16(2-4):109-14. [PubMed]

16. Yee R,McDonald N. Caries experience of 5-6-year-old and 12-13-year-old schoolchildren in central and western Nepal. Int Dent J. 2002 Dec;52(6):453-60. [PubMed I DOI]

17. Kumr A,Singh VP. Knowledge,Attitude and Practice of Oral Hygiene in Children of Eastern Nepal. IOSR J Dent Med Sci. 2014;13(6):93-9. [Full Text]

18. Koirala B,Niraula S,and Ghimire A. Estimation of Fluoride Content of Drinking Water in Dharan. Journal of B.P. Koirala Institute of Health Sciences. 2020;3(1):8895. [Full Text | DOI]

19. Lueangpiansamut J, Chatrchaiwiwatana S, Muktabhant B, Inthalohit W. Relationship between dental caries status, nutritional status, snack foods, and sugarsweetened beverages consumption among primary schoolchildren grade 4-6 in Nongbua Khamsaen school, Na Klang district, Nongbua Lampoo Province, Thailand. J Med Assoc Thai. 2012 Aug;95(8):1090-7. [PubMed]

20. Mannaa A, Carlen A,Lingstrom P. Dental caries and associated factors in mothers and their preschool and school children-A cross-sectional study. J Dent Sci 2013;8(2):101-8._[Full Text | DOI]

21. Iftikhar A,Zafar M,Kalar MU. The relationship between snacking habits and dental caries in school children. International Journal of Collaborative Research on Internal Medicine \& Public Health. 2012;4(12):1943-1951. [Full Text]

22. Khanal S,Acharya J. Dental caries status and oral health practice among 12-15 year old children in Jorpati,Kathmandu. Nepal Med Coll J. 2014 Sep;16(1):84-7. [PubMed | Full Text] 